\title{
Leprosy: Demographic and Clinical Characteristics of Patients of Endemic Area in Amazon Region
}

\begin{abstract}
Carla Andréa Avelar Pires ${ }^{1}$, Mayara Silva Nascimento ${ }^{2}$ Alyne Condurú dos Santos Cunha ${ }^{3}$, Beatriz Hosana Biasi ${ }^{3}$, Bianca Sousa de Almeida Neves ${ }^{3}$, Cynthia Luciene Pereira Alves ${ }^{3}$, Danilo dos Santos Batista ${ }^{3}$, Josué da Silva Neves Sobrinho ${ }^{3}$, Marília Brasil Xavier ${ }^{4}$
\end{abstract}

\section{Abstract}

Introduction: The hyperendemicity of leprosy in the northern region permeates regional aspects, including its large territorial extension and waterways, which make it difficult to access health and, consequently, control the disease. So that, the objective of this project is to describe the demographic and clinical profile of patients with leprosy and to evaluate their intradomiciliary contacts.

Methods and findings: Observational, descriptive study, type of case series, through interview and complementary analysis of the medical records of patients undergoing specific treatment and / or treatment of leprosy reactions followed at the Dermatology outpatient clinic of the University of the State of Pará, in the city of Belém-PA, from January 2015 to December 2017. With convenience sampling, we interviewed 83 patients that met the inclusion criteria and collected socioeconomic and demographic variables, as well as clinical aspects based on the Madrid classification. Descriptive and inferential statistical methods were applied as: tables, graphs and statistical measures of position and Test $\mathrm{G}$, with alpha significance $=0.05$ and reliability of $95 \%$. The predominance of males was observed $(60.24 \%)$, the most affected age group was between 30 and 44 years old and the majority with incomplete secondary education. The predominant family income was up to 1 minimum wage. The most frequent clinical type was Lepromatous (38 patients). Most of the patients did not present leprosy reaction and those who presented, the type 1 reaction was the most frequent and the nerve most affected was ulnar.
$1 \mathrm{PhD}$ in Medicine, Department of Dermatology and Medical Habilities, Universidade do Estado do Pará, Universidade Federal do Pará, Belém Pará, Brasil.

2 Resident in Dermatology in University of the State of Pará, Dermatology Department, Universidade do Estado do Pará, Belém, Pará, Brasil.

3 Medicine student in University of the State of Pará, Dermatology Department, Universidade do Estado do Pará, Belém, Pará, Brasil.

$4 \mathrm{PhD}$ in Medicine, Dermatology Department, Universidade do Estado do Pará and Núcleo de Medicina Tropical da Universidade Federal do Pará, Belém, Pará, Brasil.

\section{Contact information:}

\section{Carla Andréa Avelar Pires.}

Address: Universidade do Estado do Pará. Travessa Perebebuí, nº 2623, Belém. 66095-450 (Brazil).

”' carlaavelarpires@gmail.com 
Conclusion: Prevalence of multibacillary cases is a reflex of late diagnosis. It is important that there be intensification of actions and monitoring and active search for new cases.

\section{Keywords}

Leprosy; Epidemyology;

Classification.

\section{Introduction}

Leprosy is a contagious infectious disease caused by Mycobacterium leprae that affects skin and peripheral nerves, which can lead to deformities and loss of function, especially when the diagnosis is made late [1].

From 2012 to 2016, the detection of new cases of leprosy in Brazil was 14.97 cases per 100,000 inhabitants, the most affected regions were Central West and North, while the least affected were South and Southeast [2].

The state of Pará is considered hyperendemic, with a high detection rate, and represents the fifth Brazilian state in relation to the absolute number of new cases [3]. Thus, from 2012 to 2016, Pará presented about 40.39 cases for 100 thousand inhabitants, obtaining a ratio of 1.5 for male / female, that is, affecting in greater proportion the male sex [2].

The Madrid classification uses the clinical and sputum characteristics and divides leprosy into two unstable groups, indeterminate and boderline, and two stable groups, tuberculoid and lepromatous [4]. On the other hand, the Operational Classification uses the number of lesions as criterion, being paucibacillary the presence of up to five lesions and multibacillary the presence of more than five [5].

The clinical manifestations are distinguished in the classification of Madrid, which in the indeterminate form there are hypochromic spots, with undefined limits, being able to present only an alteration in perception of temperature; tuberculoide form presents lesions with well defined papulous periphery with a center without lesion, and the nerve trunks may be affected; borderline form usually have erythematous-infiltrated plaques with a very evident sensitivity alteration and the lepromatous form may have extensive areas of infiltration, besides papules and nodules (hansenomas), may also present with nerve trunks with bilateral loss of sensitivity [6].

The transmission of the disease occurs through direct contact with untreated patients, and the main route of elimination of the bacillus and also the access route in exposed individuals are the airways [7]. The risk of developing the disease among paucibacillary contacts is 2 to 3 times higher than the general population, while the risk increases to 5 to 10 times in multibacillary contacts [6].

Early diagnosis is essential to reduce transmission and to prevent new cases, considering the long incubation period of the disease. It is still recommended to investigate all the contacts of sick patients [8].

The actions of control of the disease are directed to the administration of Polychemotherapy (PCT) to those detected with leprosy and the surveillance of their contacts. In this context, the Brazilian Ministry of Health recommends that the Bacillus CalmetteGuérin (BCG) vaccine be applied to intradomiciliary contacts, without active disease, after diagnosis of the primary case [9].

In this sense, it is perceived that leprosy has a great relevance within the context of Brazil and, more specifically, of Pará, and it is important to know the peculiarities of the patients in this region. So that, this study seeks to describe the clinical and demographic characteristics of patients diagnosed 
with leprosy enrolled in the leprosy outpatient clinic of the dermatology department of University of the State of Pará, which is a reference service in the treatment of this disease.

\section{Method}

This is an observational, descriptive study, type of case series, through an interview and complementary analysis of patients' charts in follow-up at the leprosy outpatient clinic at the Dermatology Service of the University of the State of Pará, in the city of BelémPA, in the period from January 2015 to December 2017. This project was approved by the Ethics and Research Committee (CEP) of the University of the State of Pará under CAAE: 80867817.1.0000.5174 and opinion number 2,553,253 and the acceptance of the interviewee signing the Term of Free and Informed Consent.

The sample population consisted of patients over 18 years old, of both sexes, after clinical diagnosis or in cases where there was clinical doubt, with complementary diagnosis by biopsy with histopathology and who were under treatment for leprosy and / or under treatment of leprosy reaction. Patients unable to communicate verbally and those who did not agree to participate in the study were excluded.

The casuistry consisted of 83 patients, obtained through a convenience sample, since the users were invited to participate in the study at the moment of their monthly consultation in the outpatient clinic.

The research was carried out through the application of a questionnaire containing variables grouped in socioeconomic and demographic data, being: age, sex, how many people live, whether they have a home or not, level of education, profession, family income. It was also evaluated the clinical aspects of the disease, which included the following variables: Madrid classification, operational classification, presence of neuritis, leprosy reaction, whether the treatment was performed for the reaction and whether all those living with the patient were the BCG vaccine (BRASIL, 2016). The information was complemented after review of patients' medical records.

In addition, descriptive and inferential statistical methods were applied. Descriptive statistics were applied in three ways: tables, graphs and statistical measures of position. Statistical inference was implemented by means of a hypothesis test: Test $G$, which compared the proportions within the sample and between two independent samples according to the case analyzed. The level of significance alpha $=0.05$ was previously established for rejection of the null hypothesis and a reliability of 95\%. All statistical processing was carried out under the computational support of software, bioestat 5.4 and Microsoft Office Excel 2010.

\section{Results}

From the data obtained this section presents the results of this study through tables that characterize the participants according to their demographic profile. Next, the clinical aspects of the disease are characterized.

Regarding the socioeconomic characteristics presented in Table 1, the total of 83 patients, $60.24 \%$ were male, with a predominance of the age group from 30 to 44 years (37.35\%). In relation to schooling, the majority of patients attended grades $6^{\circ}$ $9^{\circ}$ (36.14\%). As for the occupation, most of them were unemployed at the time of the research (33.73\%), followed by employed (25.30\%) and retired $(21.69 \%)$ patients. The monthly income of the participants, in general, did not exceed the ceiling of three minimum wages, with the majority receiving an income of up to one minimum wage (48.19\%).

The Table 2 presents the data referring to the clinical characteristics of the study population. It was observed that $45.79 \%$ presented the clinical Lepromatous form, followed by Borderline form (38.55\%). 
Table 1. Sociodemographic characteristics of patients with leprosy.

\begin{tabular}{|c|c|c|c|}
\hline Variables & n & $\%$ & p-valor \\
\hline \multicolumn{4}{|l|}{ Gender } \\
\hline Masculine & 50 & 60.24 & \multirow{2}{*}{0.0790} \\
\hline Feminine & 33 & 39.76 & \\
\hline \multicolumn{4}{|l|}{ Age } \\
\hline$\geq 15$ and $<29$ years & 8 & 9.64 & \multirow{4}{*}{0.0043} \\
\hline$\geq 29$ e $<45$ years & 31 & 37.35 & \\
\hline$\geq 45$ e $<59$ years & 23 & 27.71 & \\
\hline$>59$ years & 21 & 25.30 & \\
\hline \multicolumn{4}{|l|}{ Schooling } \\
\hline Elementary school & 19 & 22.89 & \multirow{5}{*}{$<0.0001$} \\
\hline Middle school & 30 & 36.14 & \\
\hline High School & 24 & 28.92 & \\
\hline Higher education & 4 & 4.82 & \\
\hline No studies & 6 & 7.23 & \\
\hline \multicolumn{4}{|l|}{ Occupation } \\
\hline Self-employed & 10 & 12.05 & \multirow{5}{*}{$<0.0001$} \\
\hline Retired & 18 & 21.69 & \\
\hline Employee & 21 & 25.30 & \\
\hline Unemployed & 28 & 33.73 & \\
\hline Student & 6 & 7.23 & \\
\hline \multicolumn{4}{|l|}{ Family income } \\
\hline Up to 1 minimum wage & 40 & 48.19 & \multirow{4}{*}{$<0.0001$} \\
\hline 1 to 3 minimum wage & 38 & 45.79 & \\
\hline 3 to 6 minimum wage & 2 & 2.41 & \\
\hline No wage & 3 & 3.61 & \\
\hline Total & 83 & 100.00 & \\
\hline
\end{tabular}

Source: Protocol of the research. Chi-Square Test with.

Table 2. Distribution of patients according to the Madrid and operational classifications.

\begin{tabular}{|l|c|c|}
\hline \multicolumn{1}{|c|}{ Classification } & N (83) & $\%$ \\
\hline Madri & & \\
\hline Lepromatous & 38 & 45.78 \\
\hline Borderline & 32 & 38.55 \\
\hline Tuberculoid & 1 & 1.2 \\
\hline Indeterminate & 12 & 14.45 \\
\hline Operational & & \\
\hline Paucibacillary & 13 & 15.65 \\
\hline Multibacillary & 70 & 84.35 \\
\hline
\end{tabular}

Source: Protocol of the research. Chi-Square Test.
Approximately $61.44 \%$ of the patients did not present neuritis and, of the $21.71 \%$ who presented (32 patients), 31.25\% had ulnar involvement and $28.13 \%$ had a posterior tibial involvement (Table 3).

Regarding leprosy reactions, the vast majority of patients did not present any type of reaction (83.14\%). However, of those who presented, $12.04 \%$ had type I and 3.61\% type II (Table 4).

Regarding the vaccination of intradomiciliary contacts with the BCG vaccine, $74.69 \%$ of them were vaccinated, with $p$-value $<0.0001$ (Table 5).

Table 3. Nerves more affected in leprosy patients.

\begin{tabular}{|c|c|c|}
\hline Nerve affected & $\mathbf{N}(32)$ & $\%$ \\
\hline Auricular & 2 & 6.25 \\
\hline Tibial & 8 & 25 \\
\hline Ulnar & 10 & 31.25 \\
\hline Radial & 9 & 28.12 \\
\hline Non-specificated & 3 & 9.37 \\
\hline
\end{tabular}

Source: Protocol of the research. Chi-Square Test.

Table 4. Distribution of patients according to the types of leprosy reaction.

\begin{tabular}{|l|c|c|}
\hline \multicolumn{1}{|c|}{ Leprosy Reaction } & N $(83)$ & $\%$ \\
\hline Type I & 10 & 12.04 \\
\hline Type II & 3 & 3.61 \\
\hline Type I e II & 1 & 1.2 \\
\hline Inexistente & 69 & 83.13 \\
\hline Non-specificated & 3 & 9.37 \\
\hline
\end{tabular}

Source: Protocol of the research. Chi-Square Test.

Table 5. Vaccination history for BCG.

\begin{tabular}{|c|c|c|}
\hline BCG & $\mathbf{N}(83)$ & $\%$ \\
\hline Yes & 62 & 74.69 \\
\hline No & 21 & 25.31 \\
\hline
\end{tabular}

\section{Discussion}

After the analysis of the casuistry of the aforementioned service, a greater number of male cases (60.24\%) were observed. These data agree with the literature, because - according to Abraçada, Da 
Cunha [10], in relation to sex - there is a predominant male presence. It is believed that greater social contact between men and their frequent exposure to risky environments contributes to increase the number of cases.

In addition, the lower search for healthcare services and the lack of specific policies for this public may also contribute to the deficiency of diagnosis, which would justify the predominance of males. Other authors affirm that the preponderance of the disease in this group is not universal and that, when related to leprosy reactions, the female sex, pregnancy and breastfeeding are risk factors for the occurrence, highlighting the immunological and genetic characteristics.

In relation to age, the predominance was the involvement of people between 30-44 years old, in agreement with Miranzi, Pereira, Nunes [11], who observed a percentage of $31.4 \%$ between the age group of 34 to 49 years, and still $53.4 \%$ represent the sum of the age group of 20 to 49 years. This fact probably indicates that the economically active population is the most affected by leprosy, which can lead to significant social losses.

Another sociodemographic variable analyzed was the degree of education of the patients, in which a predominance of low level of schooling was found among leprosy patients, in agreement with the results of several other studies [12]. In the present study, a high frequency was observed in patients who had until the $9^{\text {th }}$ grade. Second, individuals who possessed until high school (Table 1). This variable is an indirect indicator of social conditions and the results reflect the relevance of this aspect for disease control. The degree of knowledge, access to the health service, understanding of the treatment guidelines and prevention measures are linked to the capacity for self-care and therapeutic adherence.

The researchers found that the frequency of patients who were unemployed was the majority. According to Simões, Delello [13], who made an association between the level of schooling and the occupation. In their analysis, the majority of patients did not have a defined profession as a result of low educational level, basically occupying general services, unemployment and underemployment.

There was also an association with low family income, since the present study showed that most of the patients had a family income of up to $1 \mathrm{mi}-$ nimum wage. This fact also agrees with the findings of Simões, Delello (2005) [13].

Regarding the clinical forms, the results are compatible with the literature Avelino et al (2015) [14]. The prevalence of lepromatous and borderline forms was observed, according to the classification of Madrid. Lepromatous and borderline forms are recognized by the great power of transmissibility and high rate of physical incapacity (Table 2 ).

In addition, the high percentage of cases with diagnosis of the disease in the multibacillary forms (lepromatous and boderline) is a strong indication that it has been diagnosed late and that the transmission chain of $M$. leprae continues to occur, serving as an alert, in view of the fact that they are considered to be contagious forms of the disease and potentially disabling. Therefore, it is necessary to discuss these data among health professionals and health management as an awareness strategy for early diagnosis and approach. The prevalence of multibacillary cases has also been demonstrated in two studies conducted in Piauí between 2011 and 2015 and in Pernambuco from 2010 to 2011 $[14,15]$.

Patients were also evaluated for the presence of neuritis. Although it has not been present in most individuals, the value obtained is still worrying, since it has important consequences for patients' quality of life and may cause irreversible sequelae.

According to Faria, Calabria [16], "neurites are reactional episodes of an inflammatory process of the peripheral nerves, manifested through pain and thickening of the peripheral nerve, loss of sensation in the areas innervated by these nerves, and loss of muscle strength innervated by these nerves". Con- 
sequently, there are still a large number of patients who are more likely to be injured by loss of sensation and physical limitations due to pain and loss of strength.

Among the patients with neuritis, the most affected nerves were the tibial, radial and ulnar nerves, with only 2 patients who had the auricular nerve affected (Table 3). It is noticed that the prevalence in the nerves of body regions most used by the patients intensifies the physical incapacitation brought by the disease. In addition, it corroborates with the literature, which states that the nerves of the upper and lower limbs most frequently affected are the ulnar and the tibial, respectively [17].

In the present study, the majority did not present a leprosy reaction (Table 4). This differ from the study conducted in Londrina in which $63.7 \%$ of the cases surveyed presented leprosy reaction. With this result, it was assumed that there was a better control of precipitating factors and stimulators of leprosy reactions, such as infections. However, it is worth mentioning that some patients may present reactional states even after the end of the multidrug therapy. The most prevalent leprosy reaction was type I, which occurs in patients with predominance of specific cellular immunity against $M$. leprae $[18$, 19].

Of the 29 cases of leprosy in the families of the interviewees, only 18 were treated. Being that of these affected relatives, 28 presented consanguineous relationship. Nonadherence to treatment directly influences the spread of the disease, especially in the family environment, with individuals directly exposed to the bacillus. In a study in the city of Jaguaré, Espírito Santo, it has been demonstrated that there is a high risk in the intradomiciliary transmission when there is a case in the family, being favored by old cases. Similarly, in the municipality of São Luís, in the state of Maranhão, $60 \%$ of the relatives had cases of consanguinity $[20,21]$.

In this research, more than half of the intradomiciliary communicators were evaluated, however, the percentage of those who were not (33\%) was still high. Among these individuals, the most prevalent reason was lack of time (work / study). This demonstrates that still have negligence regarding the care of these family communicators affected with leprosy. Although there were still missing contacts, $74.69 \%$ of them were vaccinated with BCG (Table 5).

Similarly, in an outpatient study in the state of Bahia, $74 \%$ of the contacts were evaluated, and most of them were vaccinated with BCG. The efficacy of this vaccine has been demonstrated as a protective agent of leprosy among the home contacts, since it is associated with the potentiation of the infected immune response [20, 22].

\section{Conclusion}

In this context, the prevalence of multibacillary cases is a reflex of late diagnosis. It is important to have an intensification of actions to actively search for new cases and to monitor the evaluation of the contacts examined. The continuous training of multiprofessional health teams would have benefits in terms of early diagnosis, breakdown of transmission and adequate clinical management.

\section{Competing and conflicting Interests}

The authors declare that there are no conflicts of interest.

\section{References}

1. Souza MF, Vanderlei LCM, Frias PG. Avaliação da implantação do programa de controle da Hanseníase em Camaragibe, Pernambuco. Epidemiologia e Serviços de Saúde. 2017; 26: 81734.

2. Brasil. Ministério da Saúde. Hanseníase. Boletim epidemiológico. 2018, 49 (4)

3. Albuquerque NC, Portal LC, Nogueira LMV, Rodrigues ILA. Busca ativa de hanseníase por meio de educação em saúde entre populações ribeirinhas. Rev Enferm UFPE. 2016; 10(7): 2634-40 
4. Lastoria JC, Abreu MAMM. Hanseníase: diagnóstico e tratamento. Diagn Tratam. 2012; 17(4): 173-9.

5. Campos MRM, Batista AVA, Guerreiro JV. Perfil ClínicoEpidemiológico dos pacientes diagnosticados com hanseníase na Paraíba e no Brasil, 2008-2012. Rev Bras Cienc Saúde. 2018; 22(1): 83-90.

6. Talharis PGO, Goncalves HS, Oliveira MLW. Hanseníase. 4.ed. Manaus, Brasil: Dilivros; 2015.

7. Santos DAS, Silva LCVG, Spessatto LB, Melo LS, Neto LRC. Educando para o diagnóstico precoce da hanseníase no município de Rondonópolis, Mato Grosso. Extensio: Rev Eletr de Extensão. 2016; 13(23): 45-61.

8. Ferro DA. Ações estratégicas para diagnóstico e tratamento precoce da hanseníase na unidade de saúde da família Guarapes em Natal, Rio Grande do Norte [monografia]. Natal: Universidade Federal do Maranhão - UFMA; 2017.

9. Dos Santos DS, et al. Chemoprophylaxis of leprosy with rifampicin in contacts of multibacillary patients: study protocol for a randomized controlled trial. US National Library of Medicine National Institutes of Health Search database. 2018 [acesso em 2018 maio 17]. Disponível em: https://www.ncbi.nlm.nih.gov/.

10. Abraçado MFS, Da Cunha MHCM. Adesão ao tratamento de hanseníase em pacientes com episódios reacionais hansênicos em uma unidade de referência. Rev Pan-Amaz Saúde. 2015; $6(2)$.

11. Miranzi SSC, Pereira LHM, Nunes AA. Perfil epidemiológico da hanseníase em um município brasileiro, no período de 2000 a 2006. Rev Soc Bras Med Trop. 2010; 43(1): 62-67.

12. Romao ER, Mazzoni AM. Perfil epidemiológico da hanseníase no município de Guarulhos, São Paulo. Rev Epidemiol Control Infecto. 2013; 3(1).

13. Simoes MJS, Delello D. Estudo do comportamento social dos pacientes de hanseníase do município de São Carlos, São Paulo. Rev Esp para Saúde. 2005; 7(1):

14. Avelino, AP et al. Perfil epidemiológico da hanseníase no período de 2009 a 2013 no município de Montes Claros (MG). Rev Soc Bras Clín Méd, v. 13, n. 3, p. 180-4, 2015.

15. Brito KKG, Araujo DAL, Uchoa REMN, Ferreira JDL, Soares MJGO, Lima JO. Epidemiologia da hanseníase em um estado do nordeste brasileiro. Rev Enferm UFPE online. 2014; 8(8): 268693.

16. Faria L, Calabria LK. Aspectos históricos e epidemiológicos da hanseníase em Minas Gerais. Rev Med Saúde Brasília. 2017; 6(3): 406-24.

17. Garbino JA, Junior WMA. A neuropatia da hanseníase. In: Alvez $E D$, Ferreira TL, Ferreira IN. Hanseníase Avanços e desafios. Brasília: Núcleo de Estudos em Educação e Promoção da Saúde - NESPROM/UnB; 2014. p. 215-228.

18. Sobrinho SK, Mattos ED. Perfil epidemiológico dos pacientes com hanseníase no município de Londrina, Paraná. UNOPAR Cient Cienc Biol Saúde. 2009; 11(4): 9-14.
19. Lima MM, Aguilar AMM. Perfil epidemiológico da hanseníase em um município de Minas Gerais: Uma análise retrospectiva. Rev Pre Infec e Saúde. 2015; 1(3): 1-9.

20. Rocha CA. Caracterização dos comunicantes em um ambulatório de referência para hanseníase na cidade de Salvador-Bahia [dissertação]. Salvador: Faculdade de Medicina da Universidade Federal da Bahia; 2016.

21. Peixoto BKS, Figueiredo IA, Caldas AJM, Correa RGCF, Aquino DMC. Aspectos epidemiológicos dos contatos de hanseníase no município de São Luís, Maranhão. Hansenol int online. 2011 [acesso em 2018 maio 17]. Disponível em: http://www.ilsl.br/ revista/detalhe artigo.php?id=11559.

22. Barreto ML, Pereira SM, Ferreira AA. Vacina BCG: eficácia e indicações da vacinação e da revacinação. J Pediatric. 2016; 82(3).

\section{Publish in International Archives of Medicine}

International Archives of Medicine is an open access journal publishing articles encompassing all aspects of medical science and clinical practice. IAM is considered a megajournal with independent sections on all areas of medicine. IAM is a really international journal with authors and board members from all around the world. The journal is widely indexed and classified Q2 in category Medicine. 